\title{
Ad hominem arguments in the service of boundary work among climate scientists
}

\author{
Lawrence Souder, Furrah Qureshi
}

\begin{abstract}
Most accounts of an ideal scientific discourse proscribe ad hominem appeals as one way to distinguish it from public discourse. Because of their frequent use of ad hominem attacks, the Climategate email messages provoked strong criticisms of climate scientists and climate science. This study asks whether the distinction between public and scientific discourse holds in this case and thus whether the exclusion of ad hominem arguments from scientific discourse is valid. The method of analysis comes from the field of informal logic in which argument fallacies like the ad hominem are classified and assessed. The approach in this study focuses on a functional analysis of ad hominem-their uses rather than their classification. The analysis suggests three distinct functional uses of ad hominem remarks among the Climategate emails: (1) indirect, (2) tactical, and (3) meta-. Consistent with previous research on ad hominem arguments in both public and scientific discourse, these results reinforce the common opinion of their fallacious character. Only the remarks of the last type, the meta-ad hominem, seemed to be non-fallacious in that they might help to preempt the very use of ad hominem attacks in scientific discourse.
\end{abstract}

\author{
"In this case, de Freitas is such a poor scientist that he may simply disappear." \\ (Tom Wigley, Climategate email, 1051230500.txt) ${ }^{1}$ \\ "Pielke wouldn't understand independence if it hit him in the face." \\ (Phil Jones, Climategate email, 1233249393.txt)
}

\section{Introduction $^{2}$}

As scientists-in-training, Chris de Freitas and Roger Pielke, Sr., may have suffered appropriately the sting of such remarks from an overbearing advisor on their dissertation committees in a moment of impatience. However, once these scientists were certified by their authorizing institutions, they should no longer fear such ad hominem attacks. If science proceeds as a matter of empiricism, the first and only point of judgment should be the validity of the inquiry, not the character of the inquirer. In fact, when peer review is blinded, the resulting anonymity is intended to preclude personal attacks. Thus is one of the key norms of science enforced - disinterestedness. On the assumption that de Freitas and Pielke would not reasonably expect to hear such personal attacks in a public forum their private expression is at least disturbing for their revelation of the tone of some scientists' discourse.

The tone of discourse has often troubled the participants of peer review $3,4,5,6,7,8,9$ and now since the Climategate episode it troubles the public, ${ }^{10,11}$ who pays for much of science. In November of 2009 a computer hacker infiltrated an email server at the University of East Anglia's Climatic Research Unit (CRU) and made publicly available many private messages among key climate scientists. Given the highly polarized political debate around climate science and, especially, the prospects for climate-related government regulation, some of these email messages were incendiary. It wasn't so much the scientific content of these messages that caused such a stir, but rather their unusually candid tone that provoked strong criticisms of climate scientists and climate science.

No one should be surprised that scientists, when among their closest colleagues, will let down their guard in the interests perhaps of conversational efficiency and say things like "Mike's Nature trick" and "to hide the decline" to refer to an acceptable method for combining different kinds of data sets. 
Subsequent investigations into this and other unfortunate choices of expression, in fact, have absolved the writers of any scientific wrongdoing. ${ }^{12}$ In many respects, these incendiary phrases were found to be simply scientific jargon. Nevertheless, other remarks (many of which appear in the analysis below) that implied efforts on the part of scientists to stifle dissent in the climate science community, censor data, and tamper with the peer review process provoked many to wonder: to what extent can scientists keep in check their own human impulses to be self-serving, doctrinaire, and even vindictive?

Whether these remarks reflect vicious intent or merely careless candor, the fact remains that they are thought to have besmirched the public's view of scientists and even of science. All of the pundits, in fact, along the continuum from climate change deniers to the so-called warmists are concerned for the appearance of improprieties among climate scientists. The Telegraph's politically conservative Christopher Booker predictably criticized these emails, saying: "[T]his is the worst scientific scandal of our generation." Even The Guardian's more politically moderate George Monbiot remained humble in the face of damning evidence: "[T] here are some messages that require no spin to make them look bad." Public readers of these messages may not have known the meaning of "urban heat island," but they did know that scientists should not say things like "hide the decline" when speaking about their science.

Scientists are thought to abide, whether consciously or not, by a set of norms as articulated by Merton. These norms are often institutionalized and formalized by particular scientific disciplines as codes of ethics and standards of practice. For example, on the specific matter of ad hominem attacks, the International Committee of Medical Journal Editors (ICMJE) ${ }^{13}$ states in its Uniform Requirements for Manuscripts Submitted to Biomedical Journals: "In all instances, editors must make an effort to screen discourteous, inaccurate, or libelous statements and should not allow ad hominem arguments intended to discredit opinions or findings."

Such norms are meant generally to distinguish science from other cognitive processes like deliberation and to certify the quality of the products of science. Merton notes these norms constitute a "scientific conscience," and he implies the rhetorical nature of these norms when he says, "[T]he norms are expressed in the form of prescriptions, proscriptions, preferences, and permissions". "Merton grouped these norms under the rubric of an institutional ethos of science. Prelli's notion of scientific ethos is similar but more personal: scientists embody the norms of science and profess to exemplify a certain character distinct from the character of nonscientists. ${ }^{15}$ Prelli extends this use of the classical rhetorical term ethos to claim that scientists exercise rhetoric in the support of claims of their character as much as more overt persuaders like politicians. Wander, ${ }^{16}$ in fact, assumes a rhetorical dimension in the practice of science when he asserts: "[T]he belief that something is true is secondary to a belief in the word of those sharing the information." (p. 234)

Such a claim is not so brazen, if one considers the extensive role that collaboration plays in contemporary practice of science. No research effort can succeed without the combined efforts and resources of many individual scientists and scientific communities. No one individual scientist can single-handedly carry out even the simplest discovery. Nor could any individual mount the complex justifications that must attend a scientific discovery. For these reasons, science succeeds when scientists trust each other. Hardwig, ${ }^{17}$ in fact, asserts that much of what scientists feel they know, they owe to the trust they have in the character of their fellow scientists. (p. 708)

Merton refers to this group-based knowledge as a process of "reciprocity of trust among scholars and scientists" (p. 101), which underlies his norm of communalism by which claims over intellectual property must be restrained. Moreover, Merton contends, when this process goes awry, reciprocal trust may turn into reciprocal suspicion. Disagreements over observations and interpretations may arise that quickly devolve into disagreements over the character of the observers and interpreters. Thus will develop in each camp reciprocal views of what Merton calls insiders and outsiders. From these reciprocal conceptions of each other's character, scientists in each camp formulate corollary conceptions of "insider truths" "and outsider untruths." (p. 101) Once demarcation lines are drawn between insiders and outsiders, the scientific ideal of shared knowledge is compromised.

Gieryn's historical analysis suggests an apt spatial metaphor for scientists' attempts to distinguish themselves - boundary work. Boundary work is the effort to establish a character or ethos: science has a good character, nonscience an inferior character. He makes the case that science is perceived as "objective knowledge free from emotions, private interests, bias or prejudice"18 but that the history of science does not confirm this lofty status in practice. Gieryn characterizes these attempts to establish character as dependent on strategic uses of language. His guiding question is: "[H]ow do scientists construct ideologies with style 
and content well suited to the advancement or protection of their professional authority?"19 Throughout his study, Gieryn refers to this perspective as rhetorical.

The general rhetorical strategy for addressing character is the ad hominem argument. Ad hominem arguments are usually associated with personal attacks and are regarded in contexts of formal discourse as fallacious, but appeals to character are often relevant and even central to an argument, as they are, for example, in courts of law. Ad hominem remarks confront the person behind an argument, not the content of an argument. Science by virtue of a norm like disinterestedness would like to regard all appeals to character as fallacious, but even in science they are often pertinent, as they are, for example, in the evaluation of proposals. For the most part, however, the presence of appeals to character would make science indistinguishable from other kinds of inquiry like advocacy or deliberation.

The practice of attacks on the character of scientists has been the subject of much of the literature on peer review. Walsh et al., ${ }^{20}$ for example, found that referees tended to write more courteous comments when they were not anonymous. Williams's advice for replying to referees' comments' emphasizes the importance of a civil tone. Weber et al., caution editors to mitigate harsh-sounding reviewers' comments. In a context that would understandably tempt scientists to indulge in personal attacks, Tobin, ${ }^{21}$ editor of the American Journal of Respiratory and Critical Care Medicine, announced its first retraction and stated: "Certainly, moral indignation and self-righteousness have no place in the handling of these episodes — instead, the events emphasize everyone's vulnerability and the need to stay humble."

This literature on the use of ad homimen in science offers much practical advice about avoiding them but little attention to the analysis of appropriate uses. Early theoretical views of ad hominem like Johnstone's, ${ }^{22}$ were open to non-fallacious uses. Jackson ${ }^{23}$ makes a compelling case for what he thinks is the specious distinction between public and scientific discourse, especially in the case of the human sciences where the objects of inquiry are "interactive kinds." He remains uncommitted to whether the distinction is specious in the case of the natural sciences where the objects of inquiry are "indifferent kinds." This paper attempts to discover whether a helpful distinction between public and scientific discourse holds in the case of climate science, and thus whether Walton's exclusion of ad hominem arguments from all scientific discourse is valid.

\section{Method}

A general theory of attacks on character has been the subject of much research in philosophy and rhetoric. Walton describes five types of ad hominem argument in his eponymously titled Ad Hominem Arguments: abusive, circumstantial, the bias, tu quoque, and poisoning the well. ${ }^{24}$ While the term ad hominem argument has negative connotations in the popular lexicon, Walton points out that this need not be the case, at least in the context of politics:

The problem with ad hominem arguments in political discourse is not that they are always fallacious. The problem is that character is a legitimate issue and that this legitimacy encourages a tendency to substitute soap opera for serious discussion of an issue. ${ }^{25}$

The disdain for ad hominem goes back at least to Descartes's ${ }^{26}$ Discourse on the Method, who wanted to limit legitimate arguments to logic and reason. Perelman and Olbrechts-Tyteca ${ }^{27}$ were perhaps one of the first in the last century to explicitly challenge this ideal and to include an account of the arguer in the evaluation of an argument. Leff ${ }^{28}$ among others in this century leans on Perelman to justify including ethos in his view of "argument in action" (p. 304). Johnson ${ }^{29}$ advances three conditions for evaluating arguments in action when ad hominem appeals should not be regarded as inherently fallacious: (1) the evidence to support premises is insufficient; (2) the evidence to support conclusions is insufficient; (3) the argument issues from overtly ideological perspectives.

Do any of these conditions obtain in science and thus allow for non-fallacious ad hominem arguments? In cases of insufficient evidence, science does not need to resort to ad hominem appeals because it has other ways of evaluating arguments under such conditions - by checking for validity and reliability and by replicating results. In this sense Walton is right to foreclose the possibility of non-fallacious uses of ad hominem in science on the basis of any relevance of character to the argument. Certain kinds of dialogue allow for and even invite appeals to character, such as criminal trials. Other kinds of dialogue, like critical inquiry (i.e., science) must avoid ad hominem appeals; only appeals related to the content of the arguments are allowed. 
Because the context will complicate the judgments of ad hominem arguments, their very identification can be uncertain. Our goal here is to examine the Climategate emails for ad hominem attacks that do not seem overtly provoked by concerns over evidence for premises or claims. Such attacks should be inherently fallacious in science. For other ad hominem attacks we hope to identify some ideological provocation. Johnson accepts such arguments as non-fallacious in general contexts. Gieryn points out ideological arguments as a practical component of boundary work among, for example, anatomists and phrenologists in the $19^{\text {th }}$ century. Whether such arguments remain non-fallacious in the context of science is our query. To answer this question we examine the many instances of ad hominem remarks among the Climategate email messages.

Our approach to examining ad hominem arguments will focus less on conceptual analysis and more on operational analysis. Conceptual analysis seems prone to rushing to judgment: certain types of ad hominem appeals are fallacious, others not. Even if fallacious, ad hominem remarks may be usefully examined in terms of their operation in a wider context of argument, which may be otherwise largely non-fallacious. Thus, while a conceptual view of ad hominem affirms an idealized, ahistorical, and apolitical view of science in which the very concept of ad hominem has value only to the extent that it implies some non-fallacious component, an operational view of ad hominem affirms a practical, contingent, and contextual view of science in which ad hominem is valuable even though amoral. In practice, such an approach to argument analysis must include a consideration of context. In that sense our analysis considers the contextual dimensions of Gieryn's boundary work and proceeds with his spatial metaphor as Leff does in his analysis of ad hominem arguments from a writer who, he says, "belongs to a marginalized class." 30

\section{Texts $^{31}$}

The data for this study are surrounded by extraordinary circumstances, and their use in this analysis may require some justification. The so-called Climategate email messages are publicly accessible now because in 2009 they were hacked or leaked ${ }^{32}$ from an internet server at the Climatic Research Unit at the University of East Anglia. Even though these data fall outside the purview of the university's IRB by virtue of their publicly available status, they are the property of moral agents, who can be construed indirectly as human subjects in our study. In Freedman's interview for The Washington Post, ${ }^{33}$ Spencer Weart, a science historian with the American Institute of Physics, implies such a concern when says about the moral status of the Climategate emails, "Of course no scholar can make use of stolen material, and in particular one cannot legally or ethically quote a private message without the explicit permission of the writer." Thus, we want to offer out of our concern for due diligence on matters of research ethics, a rationale for our use of the Climategate emails as data in this paper. Anyone interested in conducting publishable research on these data must confront three ethical dilemmas.

The first dilemma concerns the right to privacy. Scientists are entitled to privacy and are protected from self-incrimination, as are individual citizens, so their email messages should be secure from public view. On the other hand, employees who use their organization's email facilities cannot expect to assert the same level of ownership and privacy over their messages as they might with private individual email services. Moreover, if these emails were at the center of a larger context that involved the organization's ethical or legal transgressions, then these emails should be exposed.

The second dilemma concerns the confidentiality around the informational content of the email messages. Personal privacy matters aside, the content of scientists' emails should remain confidential if they include proprietary information or have national security issues. A host of statutes and laws precludes the publication of proprietary and classified information. On the other hand, if such proprietary- or security-related messages are associated with abuses of power, then these emails should be exposed.

Finally, the third dilemma concerns the potential status of scientists as research subjects. Researchers have ethical burdens to protect human research subjects; indirectly the authors of the Climategate emails could be considered, de facto, the research subjects in our study and thus deserve protection. On the other hand, journalists, who have similar ethical responsibilities to the subjects of their reporting, make this point moot if they have already quoted from otherwise privileged documents (e.g., Watergate).

In each of these three dilemmas, evidence for favoring the second horn seems to have prevailed, an outcome which supports the use of these email messages for research purposes. First, the access to these 
emails is now universal. Our initial source was Scribd.com, which, in fact, has an explicit "takedown" policy to remove offending documents. In addition, these emails are available from alternate sites and we are not aware of any efforts to remove these messages. Second, these messages have not been implicated in any proprietary or national security issues, but some have implied undue corporate influence of environmental policy and others have provoked investigations into the possible misconduct of climate scientists like Phil Jones, Michael Mann, and Wei-Chyung Wang. Third, the portions of the Climategate emails we include in this paper have themselves been already quoted in the popular press and internet. Journalists have then already tested the status of the email authors as research subjects. Thus, given the facts that toothpaste cannot be put back into its tube and that this toothpaste has very important implications for how scientists communicate and what impacts they have on policy decisions, we feel justified in our use of these publicly available data of otherwise dubious provenance.

\section{Context}

At the center of the context for the Climategate email messages is the Intergovernmental Panel for Climate Change (IPCC), a global clearinghouse for climate change information that will inform policy deliberations. This organization, established by the United Nations General Assembly, issues a series of assessment reports based on climate research and as such constitute reviews of research. The IPCC uses outside reviewers and editors to compile these reports.

The global climate research community contributes to the papers that support the IPCC assessment reports. Those scientists who appear in the Climategate emails are: Phil Jones, the director of the Climatic Research Unit at the University of East Anglia; Michael Mann, a paleoclimatologist a Pennsylvania State University; Keith Briffa, a dendroclimatologist at the University of East Anglia; Tom Wigley, a former director of the CRU; Benjamin Santer, a climate researcher at the Lawrence Livermore National Laboratory; Jonathan Overpeck, a geosciences researcher at the University of Arizona; and Thomas Peterson and Tom Karl, authors of IPCC assessment reports.

The review of climate science research and its assimilation into the assessment reports is a scientific peer review process, formal and often slow. Not long after 1990 when the first IPCC assessment report appeared, vibrant discussions on the internet began to produce much commentary and critique of the climate science behind the IPCC reports. These discussions have coalesced around weblogs like Steven McIntyre's ClimateAudit.org. McIntyre is not a scientist, but an engineer with special training in statistical methods. His critiques of climate scientists have centered on replicating their data analyses. Ross McKittrick, an environmental economist at the University of Guelph, has published widely on climate change. He and McIntyre authored a paper in Geophysical Research Letters, challenging the validity of Mann's hockey stick. This image, made famous by Al Gore's An Inconvenient Truth, depicts the alleged unprecedented increase in global mean temperature and became the icon that environmental activists embraced.

In response to ClimateAudit's frequent and trenchant criticism of their work, climate scientists mounted their own weblog, RealClimate.org. Behind the analysis in this paper are three conversations: (1) the informal banter among climate scientists captured in their now publicly accessible email messages; (2) the more formal and more public exchanges on the RealClimate and ClimateAudit weblogs; and (3) the formal but avowedly confidential exchanges among the parties to the review process for the IPCC assessment reports. What complicates this last conversation is the fact that often the authors, reviewers, and editors are on familiar terms with each other, behavior that apparently violates the peer review protocol in most research communities. In fact the usual boundaries in place with anonymous peer review were quite permeable as one of the climate scientists, Jonathan Overpeck admits when he says to an author, "Please be more critical with your citations so we save needed space, and also so we don't get perceived as self serving or worse" (1120014836.txt).

What makes this context of communication especially ripe for analysis are the reciprocal allegations of political and economic interests among the key players. Only the most naïve observer would deny the political motivations behind the timing of the release of the Climategate emails - on the eve of the Copenhagen climate summit in November of 2009. A more recent release of an additional 5,000 such emails seems to confirm such motivations; they coincided with the start of the December 2011 climate summit in Durban, South Africa. ${ }^{34}$ Self-proclaimed climate deniers in the political arenas reacted predictably to the first news reports about Climategate. Lord Lawson, Chancellor of the Exchequer under Margaret Thatcher, created the Global Warming Policy Foundation, whose website states: "Our main 
focus is to analyse global warming policies and their economic and other implications". 35 On the other side of the Atlantic, Republican U.S. Senator James Inhofe reported to his Environment and Public Works hearing: "[T]he scientists involved violated fundamental ethical principles governing taxpayerfunded research and, in some cases, may have violated federal laws". ${ }^{36}$

Economic motivations also are apparent among the Climategate emails. Like most academic researchers, climate scientists work tirelessly for funding from both corporate and government sources. Here is a message from Mike Hulme of the Climatic Research Unit (CRU) at the University of East Anglia, seeking a letter of support for his bid for funding from the UK government:

[T] he UK government has recently requested bids from UK universities to house a new 'National Climate Change Centre'. The Centre would receive funds of 2 million pounds sterling per year for (at least initially) five years. (0939165392.txt)

Ironically, one of the Climategate emails reveals that climate scientists were also negotiating for funds from Shell Oil - a strategy they routinely criticized among climate skeptics. Here is a message from Mick Kelly of the CRU:

Had a very good meeting with Shell yesterday. Only a minor part of the agenda, but I expect they will accept an invitation to act as a strategic partner and will contribute to a studentship fund though under certain conditions. (0962818260.txt)

Nothing is untoward in these references to funding, but they point to political and economic interests that were entangled with the communication among the scientists at the Climatic Research Unit.

\begin{abstract}
Analysis
The thousand-odd messages that constitute the Climategate emails comprise a number of both scientific and nonscientific discussions. Much of the former consist of technical discussions about climate science. The latter, however, address auxiliary, if not scientific, topics. Freedom of Information Act (FoIA) requests, for example, became a common topic when the scientists associated with the CRU were asked to publicly release their raw data because they felt besieged after so many attacks by political and corporate adversaries. Another one of their chief topics was their own peer review system when the climate scientists went on the offensive to rebut research that challenged the prevailing view of climate change. When the scientists in these emails discussed scientific matters, their remarks are for the most part related to the appropriate content. When they shift to non-scientific matters, their remarks indulge in ad hominem.
\end{abstract}

\title{
Indirect Ad Hominem
}

When the content of these emails shifted to ad hominem remarks, the authors frequently tried to do so indirectly by attacking some component that's detached from but related to the subject of the attack rather than attacking the subject directly and personally, as if to assume some critical and objective distance. In this way the attackers gave the appearance of impartiality.

When these emails addressed FoIA requests that troubled the climate scientists, they often characterized these requests in a way that by inference impugned the character of the requester, who, in this case, was often Stephen McIntyre. For instance, Schneider in his message to Santer said of McIntyre's FoIA request: "It would be odious [ $\mathrm{sic}]$ requirement to have scientists document every line of code so outsiders could then just apply them instantly," (1231257056.txt) as though the request were a metonomy for the putative odious requester, McIntyre. Santer in his message to Thorne said: "In my opinion, Mr. McIntyre's FOIA requests are for the purpose of harassing Government scientists," (1232064755.txt) implying that McIntyre, not the FOIA request, was doing the harassing. Santer in his message to Karl said: "I am unwilling to waste more of my time fulfilling the intrusive and frivolous requests of Steven McIntyre." (1226451442.txt) Although the words intrusive and frivolous in this remark grammatically modified requests, the inference is that the person who makes intrusive and frivolous requests absorbs the force of the adjectives, thus turning a judgment of an act into an attack on personal character.

The emails that address FoIA requests also included characterizations of the request process that impugn the character of the participants. Santer in his message to Karl said of McIntyre's FoIA request: "I am unwilling to submit to this McCarthy-style investigation of my scientific research." (1226451442.txt) An equivalence is implied here between McCarthy and McIntyre, thus turning a 
criticism of an investigative procedure into an ad hominem attack on an investigator. Somerville in his message to Keller about McIntyre and McKittrick said: "Their goal is not to advance the science, but to perpetuate the appearance of controversy and doubt." (1079108576.txt) The source of ad hominem here is the imputed duplicitous motives of the participants.

The emails that address FoIA requests also cast doubts about the legitimacy of the requesters as worthy recipients of the requested information. Santer in his message to Thorne said: "Neither Mr. Smith nor Mr. Stephen McIntyre ... is interested in full replication of our calculations," (1231257056.txt) as if to imply that only those who want to replicate the study are worthy of the requested information. An illegitimate request makes the requester illegitimate. Santer in one of his few messages to McIntyre himself said: "I gather that you have appointed yourself as an independent arbiter of the appropriate use of statistical tools in climate research." (1226337052.txt) Such ad hominem remarks seemed to draw a distinct boundary between accepted members of a community of science and independent agents (i.e., outsiders) who are not worthy of the community's information.

\section{Tactical ad hominem}

Even though the email messages from the CRU were not themselves part of a formal peer review, they were ancillary to and commented on that process. Moreover, although they were private communications, their tone was troubling because they reflected an apparent lack of trust and sincerity, and it seemed to betray a vulnerability to bias and a will to power - sentiments that are all contrary to the ideals of science. The remark, "If the RMS is going to require authors to make ALL data available - raw data PLUS results from all intermediate calculations - I will not submit any further papers to RMS," (1237496573.txt) suggests an impulse to horde information and seems to violate the norm of communalism. The remark, "Can any competitor simply request such datasets via the U.S. FOIA, before we have completed full scientific analysis of these datasets?" (1231257056.txt) calls into question the author's sincerity towards science's ideal of transparency and seems to violate the norm of disinterestedness. Perhaps one of the most troubling remarks is, "Kevin and I will keep them out somehow - even if we have to redefine what the peer-review literature is!" (1089318616.txt)

When the Climategate emails addressed the topic of peer review, scientists focused their remarks on agents within their own community. In these remarks they attempted to establish a boundary between legitimate and compromised peer review after they have manipulated the system to keep dissident views out. Mann, for example, objected to McIntyre and McKittrick's paper challenging his research because of their alleged conflict of interest: "The last thing this guy cares about is honest debate--he is funded by the same people as Singer, Michaels, etc..." (1104855751.txt) The emails implied that the CRU scientists attacked the credibility of McIntyre because he was not published in peer reviewed journals after they had manipulated the peer reviewed system in their field to keep him out.

One intriguing subset of the Climategate emails illustrates the writers' use of ad hominem remarks to refer to themselves, what might be called auto- ad hominem attacks. For example, when Ben Santer said, "My involvement would look too self-serving" (1228330629.txt), these scientists seemed aware of their own vulnerability to ad hominem attacks. Their acknowledgement of their own appearance of being selfserving was itself an appeal to character. Elsewhere, these scientists in moments of even greater candor were critical of their own character. When Phil Jones, for example, recounted his critique of a paper by McKittrick and Michaels, he concluded by saying "This is all gut feeling, no science, but years of experience of dealing with global scales and variability [sic]." (1098472400.txt) In another remark, which is astoundingly frank in its desperation, Jones said, "If anything, I would like to see the climate change happen, so the science could be proved right, regardless of the consequences. This isn't being political, it is being selfish" (1120593115.txt). Such auto-ad-hominem arguments complicate the issue of boundary work. The authors played the roles of both arguer and critic, and thus they seemed to cleave themselves into both scientist and nonscientist.

Another group of the Climategate emails seemed to show scientists in deliberate attempts to develop strategies for ad hominem attacks on their critics. Trenberth, for example, in a response to Jones said, "So my feeble suggestion is to indeed cast aspersions on their motives and throw in some counter rhetoric. Labeling them as lazy with nothng [sic] better to do seems like a good thing to do." (1177158252.txt) Overpeck implied an auto-ad-hominem when he offers a strategy... Tom Wigley said to Timothy Carter: "One approach is to go direct to the publishers and point out the fact that their journal is perceived as 
being a medium for disseminating misinformation under the guise of refereed work." (1051190249.txt) Mann said about McIntyre's attempts to challenge his work on RealClimate.org: "We'll use our best discretion to make sure skeptics don't get to use the RC [RealClimate] comments as a megaphone." (1139521913.txt) At some point, however, at least one of McIntyre's critics recognized some validity in his allegedly ideological committed position and acknowledged the futility of such ad hominem labels, when, for example Wigley says to Jones, "I have just read the M\&M stuff critcizing MBH. A lot of it seems valid to me." (1098472400.txt)

\section{Meta-Ad hominem}

In addition to an awareness of inappropriate discursive practices, these email messages reveal a sensitivity to ideological motives. For example, Mann said of Geophysical Research Letters: "They have published far too many deeply flawed contrarian papers" (1106322460.txt). Wigley refers to "the possible misrepresentation of the results by persons with ideological or political agendas" (1051156418.txt). Wigley identifies a specific ideological moment when he says, "I suspect that de Freitas deliberately chose other referees who are members of the skeptics camp" (1051156718.txt). Wigley then levels another ad hominem at a group of his colleagues, Legates, Balling, Lindzen, Baliunas, and Soon, "there are a number of individuals with bona fide scientific credentials who could be used by an unscrupulous editor to ensure that 'anti-greenhouse' science can get through the peer review process" (1051156718.txt). Holdren chimes in regarding Baliunas and Soon, associating them with what he calls, "ideologically committed and/or oil-industry-linked professional climate-change skeptics" (1066337021.txt).

The authors of the Climategate emails frequently indulged in ad hominem remarks despite their professed awareness of the inappropriate and ineffective nature of such remarks. For example, Tom Wigley writes about deFreitas, "He is clearly giving good science a bad name, but I do not think a barrage of ad hominem attacks or letters is the best way to counter this." (1051230500.txt) Even Michael Mann, whose publicly combative style was replete with ad hominem attacks and worried his own colleagues, once wrote to Phil Jones, "There is no room for that [ad hominem attacks] on any side of the debate." (1125067952.txt) Mann here inserted a boundary between acceptable and unacceptable scientific debate. Implied in this remark about debate is a judgment about the debaters who would use ad hominem attacks - there is no room for them either. Thus this judgment about debaters who use ad hominem is itself an ad hominem. Such messages show that the climate scientists through exchanges of forwarded messages were aware of their own ideological labels (e.g., warmists, luke-warmists). Both so-called alarmists and deniers, however, voice an occasional admission that the position of their opponent on the other side of the boundary between them may have a modicum of validity and legitimacy. Perhaps the most explicit of such admissions was Wigley's warning to Mann about corroboration of his hockey stick graph: "If I were on the greenhouse deniers' side, I would be inclined to focus on the wide range of paleo results and the difference between them as an argument for dismissing them all." (1119957715.txt) Thus Wigley in a rare self-reflexive moment offers an ad hominem remark that acknowledges the legitimacy of the deniers and makes moot the boundary that separates him from them.

The history of the outcomes of skeptics' criticisms of climate science occasionally vindicated their concerns and vitiated their critics' patronizing and abusive ad hominem remarks. It turned out that the criticisms from these skeptics should have been addressed with rebuttals related to content, not ad hominem attacks. In this case the climate scientists' anti-skeptic arguments were fallacious as a class because they seemed based on an intent to defend their character, not to defend their science. Jones's argument to deny requests for data that came from anyone associated with McIntyre's ClimateAudit website is one blatant example. Thus one can dismiss such arguments because they seem intended to fend off criticism rather than respond to it. Moreover, to label the ad hominem attacks on skeptics in this way is itself an ad hominem argument, but is it also fallacious? Since the discussion included admissions among the scientists that McIntyre's criticism had merit, his request was vindicated and their rebuff was exposed as a ploy. Thus to issue the ad hominem argument that their anti-skeptic arguments should be dismissed becomes valid. Such an ad hominem about ad hominem remarks is more that a mutual ad hominem; it can be seen as a meta-ad-hominem argument. In a sense such an ad hominem remark is a corrective to the lower-level practice of ad hominem attacks and thus appears to be a helpful, nonfallacious move in the discussion. 


\section{Conclusions}

This paper adds to the understanding of scientific discourse: (1) updated support for Gieryn's notion of boundary work among scientists; (2) a functional view of ad hominem appeals; (3) evidence for one nonfallacious use of ad hominem appeal in the context of science. Ad hominem remarks reflect a struggle to establish scientific ethos and maintain boundaries between self-legitimized scientists and their alleged illegitimate critics. In the climate science community, at least as it is illustrated in the Climategate emails, these boundaries were rhetorically fortified to both repel and inflict attacks - a practice that became characterized as their siege mentality. Such behavior is the very antithesis of the norm of universalism. For the most part the analysis of these ad hominem appeals illustrates their function in the service of Gieryn's boundary work among scientists. In particular, they use ad hominem to separate the scientist from the putative pseudo-scientist and the scientist from the putative non-scientist. For the most part, the various functional ad hominem arguments seemed to reinforce boundaries among these positions.

This analysis suggests three functional uses of ad hominem: (1) indirect, (2) tactical, and (3) meta-. The indirect ad hominem remarks seemed to model the authors' scientific ethos of objectivity by ostensibly attacking something apart from but related to the subject of their attack. The tactical ad hominem remarks recommended practical discursive interventions as an adjunct to their attacks on the character of the target. The results of analyzing these two types of functional arguments in the Climategate emails seem to confirm the fears of other studies and commentaries regarding the fallacious nature of ad hominem arguments. The third type, however, the meta- ad hominem, seemed to have a salutary effect on such problematic discourse. By commenting about the use of ad hominem remarks, these arguments seemed to dismiss arguers because of their fallacious ad hominem appeals which itself is an ad hominem appeal. However, it acknowledges and potentially reduces the ideological separation that the original ad hominem fosters.

This paper is limited by: (1) its narrow scope of data; (2) a necessarily subjective interpretation of data. Although a study of one instance is no grounds for generalizing, there is no reason to think that climate scientists and their actual modes of discourse are unique in science. If they aren't unique, then this case study of troublesome science communication warrants wider examinations. Other scientific disciplines and their discourse communities must find themselves confronted by the same social and political forces that confront climate science, especially when the stakes are high, as they are in, for example, genomics.

The results of this study point to possible future research and future practice. It suggests future research efforts to understand the use of ad hominem among scientists. This study is a case of one and as such merely exploratory. A quantitative follow-up study of ad hominem arguments in science is needed to generalize more broadly. Walton's approach, ${ }^{37}$ for example, would make the conclusions in this study more robust.

The results of this study also suggest future efforts to alter the use of ad hominem among scientists. Perhaps the most troubling impression from this analysis of scientists' discourse is the wet blanket it throws on the hopes we might have for the role of science in the larger society of which it is a part. In his ethnography of gravity wave scientists, Collins fantasized: "[S]cience done with real integrity can provide a model for how we should live and how we should judge." 38 He makes this claim not because he finds perfection in the practice of science but because he found practitioners of science in a community who openly revealed their imperfections. This community, he boasted, gave him virtually complete access to their work. On account of this transparency he felt he could trust them implicitly. As a result he concluded at the end of his analysis of the process of science that in laying bare the imperfect nature of science, the virtuous character of scientists is revealed as well-a model of behavior for the rest of us. How different is the spirit of the conclusion of this analysis. Climate science and the climate scientists who practice it are inevitably found to be as imperfect as Collins's gravity wave science and physicists. Human frailties affect science of all kinds. What distinguishes good from bad science is not the quality of scientists' results but the candor of their reporting. The scientists as represented in the Climategate emails behaved imperfectly as scientists, but their imperfections became public only after their siege mentality had been breeched by a desperate act of boundary invasion. Ironically, when done with integrity the rhetorical process of creating the boundaries that separate good from bad science might model for the rest of us the process of discerning the difference between good and bad thinking. 


\section{Notes and references}

1 Although they may be considered of questionable provenance as research data, these messages are freely accessible from many sites on the internet. The files for this study were downloaded from Scribd.com. An alternate source of the complete corpus is: $\mathrm{http}: / /$ assassinationscience.com/climategate/. In addition most of the examples quoted in this study appear as quotations in various secondary sources - most notably the popular and academic presses.

2 This paper extends an analysis that appears in Souder's report in House of Commons Science and Technology Committee, Peer review in scientific publications, Eighth Report of Session 2010-12, Volume II, Additional written evidence, (pp. 36 - 39) from which this introduction draws some of its text.

3 E. Walsh, M. Rooney, L. Appleby and G. Wilkinson (2000), Open peer review: a randomised controlled trial, British Journal of Psychiatry 176(1): 47-51.

4 E.J. Weber, P.P. Katz, J.F. Waeckerle and M.L. Callaham (2002), Author perception of peer review: impact of review quality and acceptance on satisfaction, Journal of the American Medical Association 287(21): 2790-2793.

5 H.C. Williams (2004), How to reply to referees' comment when submitting manuscripts for publication, Journal of the American Academy of Dermatology 51(1): 79-83.

6 M. Hewings (2004), An 'important contribution' or 'tiresome reading'? A study of evaluation in peer reviews of journal article submissions, Journal of Applied Linguistics 1(3), 247-274

7 H. Gosden (2003), 'Why not give us the full story?': Functions of referees' comments in peer reviews of scientific research papers, Journal of English for Academic Purposes 2(2): 87-101.

8 C.C. Miller (2006), Peer review in the organizational and management sciences: Prevalence and effects of reviewer hostility, bias, and dissensus, Academy of Management 49(3): 425-431.

9 T. Hadjistavropoulos and P.J. Bieling (2000), When reviews attack: Ethics, free speech, and the peer review process, Canadian Psychology 41(3): 152-159.

${ }^{10}$ C. Booker (2009), Climate change: this is the worst scientific scandal of our generation, The Telegraph, 28 Nov 2009. http://www.telegraph.co.uk/comment/columnists/christopherbooker/6679082/Climate-change-this-is-the-worst-scientific-scandalof-our-generation.html

${ }^{11}$ G. Monbiot (2009), Global warming rigged? Here's the email I'd need to see, The Guardian, 23 November 2009. http://www.guardian.co.uk/commentisfree/cif-green/2009/nov/23/global-warming-leaked-email-climate-scientists

${ }^{12}$ J. Randerson (2010), Climate researchers 'secrecy' criticised - but MPs say science remains intact, The Guardian, Tuesday 30 March 2010, http://www.guardian.co.uk/environment/2010/mar/31/climate-mails-inquiry-jones-cleared.

${ }^{13}$ International Committee of Medical Journal Editors, Uniform Requirements for Manuscripts Submitted to Biomedical Journals: Writing and Editing for Biomedical Publication, http://www.icmje.org/, accessed 30 July 2010.

${ }_{14}^{14}$ R. Merton (1973), The Sociology of Science; Theoretical and Empirical Investigations, Chicago, University of Chicago Press, p. 269.

${ }^{15}$ L. Prelli (1989), A rhetoric of science: Inventing scientific discourse, Charlestown, University of South Carolina Press.

${ }^{16}$ P.C. Wander (1976), The Rhetoric of Science, Western Speech Communication 40(4): 226-235.

${ }_{17}^{17}$ J. Hardwig (1991), The Role of Trust in Knowledge, Journal of Philosophy 88(12): 693-708.

${ }^{18}$ T.F. Gieryn (1983), Boundary-work and the demarcation of science from non-science: Strains and interests in professional ideologies of scientists, American Sociological Review 48(6): 781-795, pg. 785.

${ }^{19}$ T.F. Gieryn, p. 783.

${ }^{20}$ Walsh et al. (2000).

${ }^{21}$ M.J. Tobin (2000), Reporting research, retraction of results, and responsibility, American Journal of Respiratory and Critical Care Medicine 162(3): 773-774.

${ }^{22}$ H.W. Johnstone Jr., (1952), Philosophy and argumentum ad hominem, Journal of Philosophy 49: 489-498,

${ }^{23}$ J.P. Jackson Jr., (2006), Argumentum ad hominem in the science of race, Argumentation \& Advocacy 43(1): 14-28.

${ }^{24}$ D.N. Walton (1998), Ad hominem arguments, Tuscaloosa, University of Alabama Press.

${ }^{25}$ D.N. Walton (1998) p. 264.

${ }^{26}$ R. Descartes, J. Cottingham, R. Stoothoff and D. Murdoch (1984) (1991), The philosophical writings of Descartes, [Selections.English.1984], Cambridge Cambridgeshire, New York, Cambridge University Press.

${ }^{27}$ C. Perelman and L. Olbrechts-Tyteca (1969), The new rhetoric: A treatise on argumentation, Notre Dame, Ind.: University of Notre Dame Press.

${ }^{28}$ M. Leff (2009), Perelman, ad hominem argument, and rhetorical ethos, Argumentation 23(3): 301-311.

${ }^{29}$ C. Johnson (2009), Reconsidering the ad hominem, Philosophy (London) 84(02): 251-266.

${ }^{30}$ M. Leff (2009), p. 308.

${ }^{31}$ We thank Tim Raynor, Associate General Counsel, Office of the General Counsel at Drexel University for his comments on this section.

${ }^{32}$ For an analysis of the various explanations for the appearance of the Climategate email messages see Leigh et al. (2010), Climate emails: were they really hacked or just sitting in cyberspace?, The Guardian, Thursday 4 February 201012.14 EST, http://www.guardian.co.uk/environment/2010/feb/04/climate-change-email-hacker-police-investigation.

${ }^{33}$ A. Freedman (2009), Posted at 11:00 AM ET, 11/23/2009, Science historian reacts to hacked climate e-mails, The Washington Post, http://voices.washingtonpost.com/capitalweathergang/2009/11/perspective_on_a_climate_scien.html.

${ }^{34}$ L. Hickman (2011), Fresh round of hacked climate science emails leaked online, The Guardian, Tuesday 22 November 2011, http://www.guardian.co.uk/environment/2011/nov/22/fresh-hacked-climate-science-emails.

${ }^{35}$ GWPF (2009), Who we are, Global Warming Policy Foundation, Thursday, 19 November 2009, http://www.thegwpf.org/whowe-are/history-and-mission.html.

${ }^{36}$ S. Goldenberg (2010), US Senate's top climate sceptic accused of waging 'McCarthyite witch-hunt', The Guardian, Monday 1 March 2010, http://www.guardian.co.uk/environment/2010/mar//01/inhofe-climate-mccarthyite.

${ }^{37}$ D. Walton (2010), Formalization of the ad hominem argumentation scheme, Journal of Applied Logic 8(1): 1-21.

${ }^{38}$ H.M. Collins (2011), Gravity's ghost: Scientific discovery in the twenty-first century, University of Chicago Press, Chicago, p. 3. 


\section{Authors}

Lawrence Souder earned his Ph.D. in the rhetoric of science from Temple University. He is on the graduate faculty of Culture and Communication at Drexel University. Souder's research is focused on the ethics of the scholarly peer review process. E-mail: LS39@drexel.edu.

Furrah Qureshi is a graduate student in the master's program in public communication at Drexel University. She has also served as the editor-in-chief of _The Triangle_, Drexel's independent, studentrun newspaper. E-mail: furrah.qureshi@gmail.com.

How tO CITE: L. Souder and F. Qureshi, Ad hominem arguments in the service of boundary work among climate scientists, Jcom 11(01) (2012) A01. 